\title{
Beneficial Effects of a Perindopril/Indapamide Single- Pill Combination in Hypertensive Patients with Diabetes and/or Obesity or Metabolic Syndrome: A Post Hoc Pooled Analysis of Four Observational Studies
}

Csaba Farsang · Csaba Andras Dézsi · Romualda Brzozowska-Villatte •

Martine De Champvallins · Maria Glezer · Yuri Karpov

Received: December 16, 2020 / Accepted: January 5, 2021 / Published online: February 25, 2021

(C) The Author(s) 2021

\section{ABSTRACT}

Introduction: To assess real-life effectiveness of a perindopril/indapamide (Per/Ind) single-pill combination (SPC) in patients with hypertension (HT) and type 2 diabetes mellitus (T2DM), obesity and/or metabolic syndrome (MetS).

Supplementary Information The online version contains supplementary material available at https:// doi.org/10.1007/s12325-021-01619-8.

C. Farsang ( $\square)$

Semmelweis University Pharmacology and

Therapeutics and St. Imre University Teaching

Hospital, Budapest, Hungary

e-mail: hunghyp@t-online.hu

C. A. Dézsi

Department of Cardiology, Petz Aladár County

Teaching Hospital, Gyor, Hungary

R. Brzozowska-Villatte

Global Medical and Patient Affairs Department,

Servier, Suresnes, France

M. De Champvallins

Institut de Recherches Internationales Servier,

Suresnes, France

M. Glezer

Department of Preventive and Emergency

Cardiology, Sechenov First Moscow State Medical

University, Moscow, Russia

Y. Karpov

National Medical Research Centre of Cardiology,

Moscow, Russia
Methods: This post hoc analysis pooled raw data from four large observational studies (FORTISSIMO, FORSAGE, ACES, PICASSO). Patients, most with uncontrolled blood pressure (BP) on previous treatments were switched to Per/Ind $(10 \mathrm{mg} / 2.5 \mathrm{mg})$ SPC at study entry. Office systolic and diastolic blood pressures (SBP and DBP) were measured at baseline, 1 month and 3 months.

Results: In the overall pooled population $(N=16,763)$, mean age was $61 \pm 12$ years, HT duration $11 \pm 8$ years, and baseline SBP/DBP 162/94 mmHg. T2DM, obesity and MetS were present in $21 \%, 49 \%$ and $27 \%$ of patients, respectively. Subgroups had similar mean age and HT duration to the overall population; patients with T2DM were slightly older (64 \pm 10 years) with a longer HT duration (13 \pm 8 years). Mean BP was approximately $160 / 95 \mathrm{mmHg}$ in each subgroup. At 1 month, mean SBP decreased by approximately $20 \mathrm{mmHg}$ in the overall population, and by a further $10 \mathrm{mmHg}$ at 3 months. Similar results were observed in the three subgroups, with mean changes from baseline at 3 months of $-28 \pm 15 /-13 \pm 10$ in T2DM; $-30 \pm$ $15 /-14 \pm 10$ in obesity; and $-31 \pm 15 /-15 \pm$ $9 \mathrm{mmHg}$ in MetS. BP decreases were greatest in patients with grade II or grade III HT. BP control rates $(<140 / 90 \mathrm{mmHg}$ or $140 / 85 \mathrm{mmHg}$ for $\mathrm{T} 2 \mathrm{DM})$ at 3 months were $59 \%$ in T2DM, $67 \%$ in obese, and $66 \%$ in MetS. No specific safety 
concerns were raised, particularly concerning ionic $(\mathrm{Na}, \mathrm{K})$ or metabolic profiles.

Conclusions: Switching to Per/Ind SPC led to rapid and effective $\mathrm{BP}$ decreases in patients with T2DM, obesity, or MetS. BP control was achieved in 6-7 out of 10 previously treated but uncontrolled patients. Treatment was well tolerated. The results confirm the beneficial effects of a Per/Ind SPC for difficult-to-control patient populations.

Keywords: Blood pressure control; Hypertension; Indapamide; Metabolic syndrome; Obesity; Perindopril; Single-pill combination; Type 2 diabetes mellitus

\section{Key Summary Points}

\section{Why carry out this study?}

Patients with metabolic disorders such as type 2 diabetes mellitus (T2DM), obesity and/or metabolic syndrome (MetS) have a significantly higher prevalence of hypertension, and are increasing in numbers in most parts of the world.

This population is often referred to as difficult-to-treat (blood pressure [BP] control rates much lower compared with individuals without these comorbidities), elevating the global risk of hypertension and cardiovascular disease and hence the burden on healthcare systems.

Current guidelines for the management of hypertension (ESC/ESH, ACC/AHA, ISH) do not provide any specific recommendations for pharmacological strategies among patients with obesity or those with MetS, but recommend the preferential use of a single-pill combination (SPC) and patient management which takes into account the presence of other cardiovascular risk factors.
Four large observational prospective studies assessed the efficacy of a perindopril $10 \mathrm{mg} /$ indapamide $2.5 \mathrm{mg}$ (Per10/Ind2.5) SPC in patients with hypertension uncontrolled on their previous treatment. Patients had a range of associated risk factors and comorbidities, making the cohort representative of patients followed in daily medical practice.

The raw data from these studies were pooled to provide results in cohorts of sufficient sample size to assess the SPC effects over 3 months in a large pooled analysis performed with the high dose Per/Ind SPC consisting of 16,763 patients.

\section{What was learned from the study?}

The results of our three subgroup analyses of patients enrolled in four large, 3-month, observational trials (FORTISSIMO, FORSAGE, PICASSO, and ACES) indicate that the Per/Ind SPC $(10 \mathrm{mg} / 2.5 \mathrm{mg}$ ) provides effective and well-tolerated BP-lowering in patients with previously treated but uncontrolled hypertension and associated metabolic disorders (T2DM and/or obesity or MetS), i.e. populations in whom it is recognized that BP is difficult-to-control.

For each analysed subgroup, the switch to Per/Ind SPC provided significant BP decreases from baseline that were already observed after 1 month.

At study end, BP control was achieved in 6-7 out of 10 previously treated but uncontrolled patients: obesity (67\%), MetS (66\%), and T2DM (59\%).

In these subgroups, treatment with the Per/Ind SPC was safe, metabolically neutral (no impact on glucose and lipid parameters) and emergent adverse events were relatively infrequent. 


\section{DIGITAL FEATURES}

This article is published with digital features, including a summary slide, to facilitate understanding of the article. To view digital features for this article go to https://doi.org/10.6084/ m9.figshare.13521743.

\section{INTRODUCTION}

High arterial blood pressure (BP) is the leading risk factor for adverse cardiovascular events, kidney disease and premature mortality, and is perhaps ultimately responsible for $13 \%$ of deaths worldwide as compared to $5.8 \%, 4.8 \%$ and $4.5 \%$ for diabetes, obesity and hypercholesterolaemia, respectively [1]. Recent estimates indicate the prevalence of adult hypertension (systolic blood pressure [SBP]/diastolic blood pressure $[\mathrm{DBP}] \geq 140 / 90 \mathrm{mmHg}$ ) in Europe is at least $40 \%[2,3]$. Hypertension becomes progressively more common with advancing age, and in individuals aged over 60 years the prevalence may be greater than $60 \%$ [4]. Additional cardiovascular disease (CVD) risk factors commonly associated with hypertension include type 2 diabetes mellitus (T2DM, present in 15-20\% of patients with hypertension), lipid disorders (30\%), overweight/obesity (40\%) and metabolic syndrome (MetS) (40\%) [5].

T2DM and obesity are increasingly prevalent in most parts of the world, elevating the global risk of hypertension and CVD and hence the burden on healthcare systems [6, 7]. Patients with MetS, a combination of risk factors that include central obesity, raised fasting glucose, dyslipidaemia and hypertension, comprise an additional risk group [8]. A residual cardiovascular risk is still present in many of these patients despite widespread use of cardiometabolic medications.

The prevalence of MetS in the USA was recently estimated at 34\% [9], and one European estimate in a large cohort from 10 countries was $24 \%$ (closer to $25 \%$ for women) [10]. Compared to the general population, individuals with obesity and those with T2DM have a significantly higher prevalence of hypertension.
Up to $75 \%$ of individuals with obesity seen in primary care have hypertension [11], and $81 \%$ of patients with T2DM [12]; less than $30 \%$ of these individuals reach recommended levels of BP control [13].

The clustering of pathologies (hypertension/ obesity/T2DM/MetS) is believed to be due to common dysfunctions of neurohumoral feedback and the sympathetic control of the kidneys and heart $[14,15]$. Increased visceral adiposity contributes not only to the sustained stimulation of the sympathetic nervous system (promoting $\mathrm{Na}^{+}$retention, renal microvascular remodelling and arterial stiffness [15]) but is also pro-oxidative and leads to a proinflammatory state. This subsequently causes insulin resistance and impairs glucose utilisation through actions on the endothelium (vascular rarefaction, vascular remodelling, reductions in vascular relaxation) and has implications for other tissues that affect BP regulation. Together, these metabolic/hormonal imbalances augment CVD risk, the level of which is also influenced by age and gender [16].

Patients with hypertension and comorbid T2DM, obesity or MetS are therefore often referred to as difficult-to-treat populations, as it has become clear that BP control rates in such patients tend to be much lower compared with individuals without these comorbidities. Frequently, this poor control continues despite the use of supplementary antihypertensive medications $[14,17]$.

In such difficult-to-treat populations, clinical decisions need to be based on pathophysiological rationale. Identification of the most appropriate drug regimen should take into account the mechanism of obesity-related hypertension, which involves a complex interplay of underlying pathologies such as enhanced activity of the sympathetic nervous system and renin-angiotensin system (RAS), the activity of several adipocyte-derived substances, increased renal tubular sodium reabsorption, vascular endothelial dysfunction and insulin resistance [18]. As BP reductions in these populations only partially address the pathophysiological pathways, and significant residual risk is observed even amongst those with controlled BP [19], an integrated cardiovascular risk management 
approach should be adopted, involving aggressive BP control and use of antihypertensive agents known to have protective benefits beyond BP lowering.

Current guidelines for the management of hypertension, including those of the European Society of Cardiology/European Society of Hypertension (ESC/ESH) [2], the American College of Cardiology/American Heart Association (ACC/AHA) [20], and the latest International Society of Hypertension (ISH) 2020 guidelines [5], do not provide any specific recommendations for pharmacological strategies among patients with obesity or those with MetS other than those related to lifestyle behaviour. To date, few prospective trials have been conducted to determine the ideal antihypertensive regimen for patients with obesity and MetS [21]. Guideline recommendations for preferred choice of antihypertensive drugs in the management of T2DM do exist, however, and advise use of a RAS blocker, calcium channel blocker (CCB) and/or thiazide-like diuretic [2, 5, 22, 23], based on results from the ADVANCE (Action in Diabetes and Vascular Disease: Preterax and Diamicron Modified Release Controlled Evaluation) study, among others, which assessed the cardiovascular event reduction associated with perindopril/indapamide (Per/Ind) single-pill combination (SPC) in patients with T2DM [24]. Clinical decisions for individuals who are obese or have MetS are made on a case-by-case basis using pathophysiological criteria to identify the most appropriate drug regimens. As sustained sympathetic overdrive is considered the cardinal feature of obesity, a RAS blocker (i.e. angiotensin-converting enzyme inhibitor [ACEi] or angiotensin receptor blocker [ARB]) is commonly used first with either a CCB and/or a diuretic; the combination of a RAS blocker with a thiazide-like diuretic is also supported [25].

In the present analysis, we investigated the efficacy and safety of a Per/Ind SPC in these difficult-to-treat subgroups of patients, using pooled data from four similar, large observational studies conducted in Eastern Europe [26]. The Per/Ind SPC provides an optimised ratio of two recommended major drug classes of antihypertensive agents, which in addition to providing reliable $\mathrm{BP}$ reduction, have cardioprotective properties that could be valuable in patients with hypertension and metabolic abnormalities [27, 28].

The results of the overall population in this pooled analysis as well as the response of patients with isolated systolic hypertension and by age class and gender are presented separately [26]. Data from this pooled analysis have previously been presented at the meeting of the International Society of Hypertension in 2018 and published as two abstracts: Dézsi and colleagues reported the results in patients with obesity and Farsang for patients with T2DM $[29,30]$.

\section{METHODS}

The methodology for this subgroup pooled analysis has been fully described elsewhere [26]. Briefly, individual patient data from four large, prospective, observational studies (FORTISSIMO [Full-dose Perindopril/Indapamide in the Treatment of Difficult-to-Control Hypertension] [31]; FORSAGE [How to Increase the Effectiveness of Antihypertensive Therapy in Clinical Practice] [32]; ACES [Antihypertensive Combinations' Long Term Efficacy Comparing Study] [33]; and PICASSO [Perindopril Plus Indapamide Combination Blood Pressure Reduction] [34, 35]) were integrated into a single database. The four studies had similar designs, study endpoints (office sitting SBP/ DBP), time points (1- and 3-month visits) and reported information. At baseline, patients switched from their existing antihypertensive treatment to the Per/Ind SPC 10/2.5 mg.

Obesity was defined as body mass index (BMI) greater than $30 \mathrm{~kg} / \mathrm{m}^{2}$ (FORTISSIMO and FORSAGE); or a waist circumference greater than $102 \mathrm{~cm}$ for men, greater than $88 \mathrm{~cm}$ for women (ACES and PICASSO).

A diagnosis of MetS was made if a patient had at least three of the following criteria (essentially derived from the National Cholesterol Education Program Expert Panel (NCEP) and Adult Treatment Panel III [ATP III]) [36]:

- Obesity (as defined above) 
- Low high-density lipoprotein (HDL) cholesterol $(<1.04 \mathrm{mmol} / \mathrm{L}$ for $\mathrm{men} ;<1.29 \mathrm{mmol} / \mathrm{L}$ for women)

- High triglycerides $(\geq 1.69 \mathrm{mmol} / \mathrm{L})$

- Presence of T2DM or high plasma levels of fasting glucose $(\geq 6.1 \mathrm{mmol} / \mathrm{L})$

- High BP (SBP > $130 \mathrm{mmHg}$ and DBP $>85 \mathrm{mmHg}$ )

MetS was not defined for patients in the FORSAGE study as data on plasma glucose, HDL-cholesterol and triglycerides were not available.

Existing information about adverse events was pooled. The main endpoints were mean changes in SBP and DBP from baseline and the proportions of patients achieving target BP $(<140 / 90 \mathrm{mmHg}$, but $<140 / 85 \mathrm{mmHg}$ for patients with T2DM in any subgroup).

The designs of the individual studies in this pooled analysis were approved by local ethics committees. Information on the individual local ethics committees for each of the studies can be found in the primary study publications. All studies were carried out in accordance with the ethical principles derived from the revised Declaration of Helsinki. All patients provided written informed consent.

\section{RESULTS}

The pooled analysis of the four studies included 16,763 patients with a mean age $( \pm S D)$ of $61 \pm 12$ years, $57 \%$ of whom were women, with a mean hypertension duration of $11 \pm 8$ years. In the overall population, $21 \%(n=3450)$ had T2DM, 49\% $(n=8113)$ were obese and $27 \%$ $(n=4448)$ had MetS. The main demographic data for the three patient subgroups are summarized in Table 1.

The subgroups of patients with obesity and MetS had similar mean ages to the overall population (whole cohort) $(61 \pm 11$ and $62 \pm 11$ years, respectively) and had a similar mean hypertension duration (both 11 years). Patients in the T2DM subgroup, on the other hand, tended to be slightly older (mean age $64 \pm 10$ years) and had a slightly longer hypertension duration (13 \pm 8 years).
The mean baseline SBP/DBP in the overall population was 162/94 $\mathrm{mmHg}$. About one-third of patients $(35 \% ; n=5875)$ had grade I hypertension (SBP $>140$ and $<160 \mathrm{mmHg}$ ), $48 \%$ $(n=8032)$ had grade II hypertension (SBP $\geq 160$ and $<180 \mathrm{mmHg}$ ) and $13 \%(n=2242$ patients $)$ had grade III hypertension (SBP > $180 \mathrm{mmHg}$ ). (Note: the remaining $4 \%$ of patients had, at baseline, either fluctuating BP or controlled BP with adverse drug reactions.) In the T2DM, obese and MetS subgroups, the proportions of patients according to hypertension grade were fairly similar to the whole cohort: $36 \%, 46 \%$ and $13 \%$, respectively, for patients with T2DM, $32 \%, 50 \%$ and $14 \%$, respectively, for patients with obesity, and $33 \%, 50 \%$ and $14 \%$, respectively, for patients with MetS. Risk factors and co-morbidities were generally more frequent in these patient subgroups than in the whole cohort. This was particularly the case for diagnoses of coronary artery disease (CAD) or myocardial infarction (MI) $39 \%$ in patients with T2DM, 31\% in patients with obesity and $37 \%$ in patients with MetS, but only $28 \%$ in the whole cohort); proteinuria and chronic kidney disease were also more prevalent in the subgroup populations (Table 1 ).

In this population of patients with uncontrolled BP, the switch to Per/Ind SPC (10/ $2.5 \mathrm{mg}$ ) led to marked decreases in mean BP both at 1 month and 3 months for each subgroup. The changes were significant both statistically $(p<0.001)$ as well as clinically, for each BP phase (systolic and diastolic) (Table 2).

After 1 month of treatment, the mean decreases in SBP exceeded $-20 \mathrm{mmHg}$ in each subgroup. After 3 months, SBP/DBP decreases from baseline were similar in patients with obesity and in patients with MetS $(-30 /-15 \mathrm{mmHg}$ and $-31 /-16 \mathrm{mmHg}$, respectively), as were the final mean BP values $(132 \pm 10 / 80 \pm 6 \mathrm{mmHg}$ and $133 \pm 10 /$ $81 \pm 10 \mathrm{mmHg}$, respectively). In patients with T2DM, who are regarded as the most difficult subgroup to treat, the mean BP decreases were slightly lower, at $-28 /-13 \mathrm{mmHg}$, but reached the same final mean $\mathrm{BP}$ value $(133 \pm 10 / 80 \pm 7 \mathrm{mmHg})$.

At study end, $67 \%$ of obese and $66 \%$ of the patients with MetS achieved BP control, slightly 
Table 1 Population demographics, medical history and baseline vital signs

\begin{tabular}{|c|c|c|c|c|}
\hline & $\begin{array}{l}\text { Patients with } \\
\text { diabetes } \\
(N=3450)\end{array}$ & $\begin{array}{l}\text { Patients with } \\
\text { obesity } \\
(N=8113)\end{array}$ & $\begin{array}{l}\text { Patients with } \\
\text { MetS } \\
(N=4448)\end{array}$ & $\begin{array}{l}\text { Whole } \\
\text { cohort } \\
(N=16,763)\end{array}$ \\
\hline \multicolumn{5}{|l|}{ Patient demographics } \\
\hline Age, mean $\pm S D$ (years) & $64 \pm 10$ & $61 \pm 11$ & $62 \pm 11$ & $61 \pm 12$ \\
\hline$>65, n(\%)$ & $1531(44)$ & $2839(35)$ & $1616(36)$ & $6052(36)$ \\
\hline Female gender, $n(\%)$ & $1938(57)$ & $4863(61)$ & $2619(60)$ & $9369(57)$ \\
\hline $\begin{array}{l}\text { Disease duration, mean } \pm S D \\
\text { (years) }\end{array}$ & $13 \pm 8$ & $11 \pm 8$ & $11 \pm 8$ & $11 \pm 8$ \\
\hline \multicolumn{5}{|l|}{ Risk factors and medical history } \\
\hline Diabetes mellitus, $n(\%)$ & $3450(100)$ & $2253(28)$ & $1602(36)$ & $3450(21)$ \\
\hline Obesity, $n(\%)^{\mathrm{a}}$ & $2253(65)$ & $8113(100)$ & $3605(81)$ & $8113(49)$ \\
\hline Dyslipidemia, $n(\%)$ & $1905(67)$ & $3654(60)$ & $2409(68)$ & $6456(51)$ \\
\hline Tobacco consumption, $n(\%)$ & $734(22)$ & $1987(25)$ & $1132(26)$ & $4694(28)$ \\
\hline Coronary artery disease/MI, $n(\%)$ & $1342(39)$ & $2522(31)$ & $1624(37)$ & $4699(28)$ \\
\hline Chronic heart failure, $n(\%)$ & $643(24)$ & $1589(24)$ & $754(20)$ & $3122(23)$ \\
\hline Cerebrovascular accident, $n(\%)$ & $522(15)$ & $922(12)$ & $562(13)$ & $1914(12)$ \\
\hline Atherosclerosis, $n$ (\%) & $964(34)$ & $1692(28)$ & $1031(29)$ & $3397(27)$ \\
\hline Retinopathy, $n$ (\%) & $354(33)$ & $1229(45)$ & $863(54)$ & $1927(38)$ \\
\hline Proteinuria/microalbuminuria, $n(\%)$ & $534(17)$ & $709(10)$ & $561(13)$ & $1055(7)$ \\
\hline Renal disease, $n(\%)$ & $233(8)$ & $309(5)$ & $217(6)$ & $512(4)$ \\
\hline \multicolumn{5}{|l|}{ Vital signs (office) } \\
\hline $\mathrm{SBP}$, mean $\pm \mathrm{SD}(\mathrm{mmHg})$ & $161 \pm 15$ & $163 \pm 14$ & $163 \pm 14$ & $162 \pm 15$ \\
\hline $\mathrm{DBP}$, mean $\pm \mathrm{SD}(\mathrm{mmHg})$ & $94 \pm 10$ & $95 \pm 9$ & $96 \pm 8$ & $94 \pm 9$ \\
\hline Heart rate, mean $\pm S D(b p m)$ & $79 \pm 9$ & $79 \pm 9$ & $79 \pm 9$ & $79 \pm 9$ \\
\hline
\end{tabular}

Data are presented as mean \pm SD or $n(\%),(\%)=(n /$ nobs $) \times 100$ with nobs $=$ number of patients with available information by parameter; patients were switched to SPC at baseline: $94 \%$ of patients were treated with the Per 10/Ind 2.5 SPC, the remainder received Per5/Ind1.25

$M e t S$ metabolic syndrome, $M I$ myocardial infarction, $S B P$ systolic blood pressure, $D B P$ diastolic blood pressure

${ }^{a}$ Body mass index $>30 \mathrm{~kg} / \mathrm{m}^{2}$ or waist circumference $>102 \mathrm{~cm}$ in men, $>88 \mathrm{~cm}$ in women 
Table 2 Effect of treatment in patient subgroups: baseline blood pressure and change after 1 month and 3 months of treatment

\begin{tabular}{lcccc}
\hline BP $(\mathbf{m m H g} \pm \mathbf{S D})$ & \multicolumn{1}{c}{ Diabetes } & Obesity & MetS & Whole cohort \\
\hline Baseline SBP & $161 \pm 15$ & $163 \pm 14$ & $163 \pm 14$ & $162 \pm 15$ \\
$\Delta$ at 1 month & $-21 \pm 14$ & $-23 \pm 14$ & $-23 \pm 14$ & $-23 \pm 14$ \\
$\Delta$ at 3 months & $-28 \pm 15$ & $-30 \pm 15$ & $-31 \pm 15$ & $-30 \pm 15$ \\
SBP at 3 months & $133 \pm 10$ & $132 \pm 10$ & $133 \pm 10$ & $131 \pm 10$ \\
Baseline DBP & $94 \pm 10$ & $95 \pm 9$ & $96 \pm 8$ & $94 \pm 9$ \\
$\Delta$ at 1 month & $-10 \pm 9$ & $-11 \pm 9$ & $-11 \pm 9$ & $-11 \pm 9$ \\
$\Delta$ at 3 months & $-13 \pm 10$ & $-15 \pm 10$ & $-16 \pm 9$ & $-14 \pm 10$ \\
DBP at 3 months & $80 \pm 7$ & $80 \pm 6$ & $81 \pm 6$ & $80 \pm 6$ \\
\hline$\Delta$
\end{tabular}

$\Delta$ change from baseline to visit

$B P$ blood pressure, $M e t S$ metabolic syndrome, $S B P$ systolic blood pressure, $D B P$ diastolic blood pressure

Table 3 Blood pressure control rates at 3 months in the patient subgroups according to baseline SBP severity and overall

\begin{tabular}{lllll}
\hline BP control at 3 months & $\begin{array}{l}\text { Mild HT (\%) } \\
\text { (grade I) }\end{array}$ & $\begin{array}{l}\text { Moderate HT (\%) } \\
\text { (grade II) }\end{array}$ & $\begin{array}{l}\text { Severe HT (\%) } \\
\text { (grade III) }\end{array}$ & Overall (\%) \\
\hline Diabetes subgroup & 72 & 54 & 42 & 60 \\
Obese subgroup & 78 & 65 & 49 & 68 \\
MetS subgroup & 76 & 64 & 49 & 66 \\
Whole cohort & 80 & 67 & 53 & 70 \\
\hline
\end{tabular}

$B P$ blood pressure, $H T$ hypertension, $M e t S$ metabolic syndrome

higher than the proportion achieving BP control in the T2DM subgroup (59\%); however, the definition of BP control in the T2DM subgroup had a lower DBP target $(<140 / 85 \mathrm{mmHg})$ (Table 3).

As expected, the decreases in SBP were more pronounced in patients with grade II and grade III hypertension than in those with grade I hypertension and the results were similar for all subgroups (Fig. 1 for the T2DM subgroup). BP control rates were higher in patients with grade I and grade II hypertension than in those with grade III.

In these high-risk subgroups with co-morbidities, treatment with the Per/Ind SPC was safe and emergent adverse events were relatively infrequent. The events that did occur were generally well-documented, drug-related events
(Table 4), most frequently dizziness, cough and peripheral oedema. In the T2DM subgroup, these events occurred at rates of $0.2 \%$, as compared to $0.3 \%$ in the obese subgroup (for dizziness and cough) and $0.4 \%$ in the MetS subgroup. Serious events were reported by $0.4 \%$, $0.3 \%$ and $0.4 \%$ in the diabetes, obese, and MetS subgroups, respectively, and the system organ classes (SOC) affected are presented in Table 4. Only two preferred terms reached the threshold of $0.1 \%$ incidence: two cases of unexplained death (SOC General disorders) and two cases of "death of relative" (SOC Social circumstances). Further details are provided in Supplementary Table 1.

In the overall population and in the three subgroups, the results for serum levels of sodium $\left(\mathrm{Na}^{+}\right)$, potassium $\left(\mathrm{K}^{+}\right)$, creatinine and 


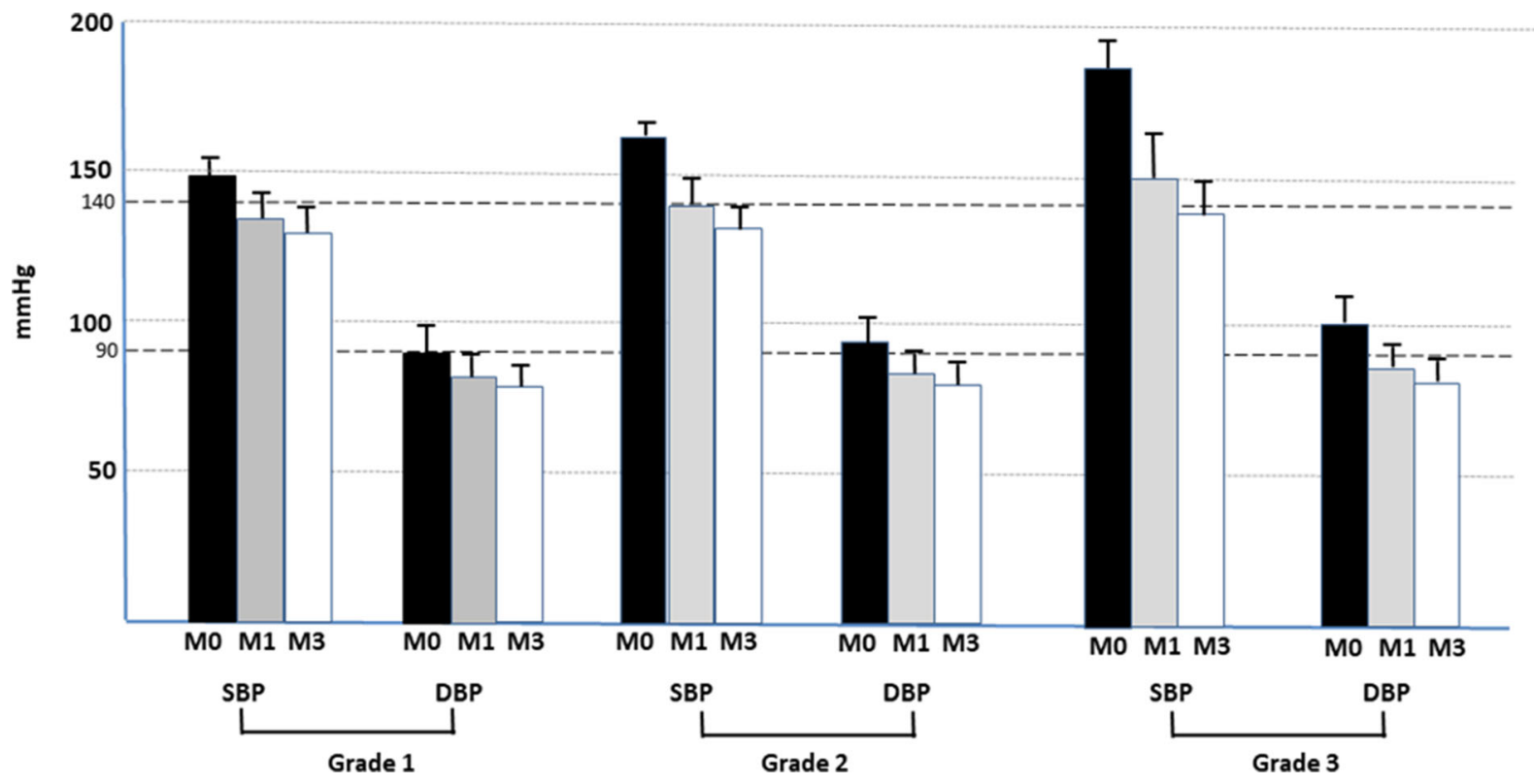

Fig. 1 Effect of treatment on blood pressure in the diabetes subgroup according to baseline SBP severity. M0, baseline. M1, 1 month. M3, 3 months

Table 4 Adverse events emergent under treatment: percentage of patient affected for events with at least $0.2 \%$ patients (or more than two patients with a serious event) in any group

\begin{tabular}{lllll}
\hline System organ class (\%) & $\begin{array}{l}\text { Diabetes } \\
(\boldsymbol{N}=\mathbf{3 4 5 0})\end{array}$ & $\begin{array}{l}\text { Obesity } \\
(\boldsymbol{N}=\mathbf{8 1 1 3})\end{array}$ & $\begin{array}{l}\text { Metabolic syndrome } \\
(\boldsymbol{N}=\mathbf{4 4 4 8})\end{array}$ & $\begin{array}{l}\text { Whole cohort } \\
(\boldsymbol{N}=\mathbf{1 6 , 7 6 3})\end{array}$ \\
\hline $\begin{array}{l}\text { Preferred term (\%) } \\
\text { All }\end{array}$ & $1.7(n=13)$ & $1.7(n=24)$ & $2.1(n=19)$ & $1.3(n=35)$ \\
$\begin{array}{l}\text { General disorders and } \\
\text { administration site conditions }\end{array}$ & $0.6(n=3)$ & $0.5(n=6)$ & $0.7(n=3)$ & $0.3(n=8)$ \\
$\quad$ Oedema peripheral & 0.2 & 0.2 & 0.3 & 0.1 \\
Nervous system disorders & $0.4(n=1)$ & $0.5(n=4)$ & $0.6(n=4)$ & $0.4(n=6)$ \\
$\quad$ Dizziness & 0.2 & 0.3 & 0.4 & 0.2 \\
$\quad$ Headache & 0.1 & 0.2 & 0.2 & 0.1 \\
Respiratory, thoracic and & $0.2(n=1)$ & $0.4(n=1)$ & $0.4(n=1)$ & $0.3(n=1)$ \\
mediastinal disorders & & & 0.3 & 0.3 \\
$\quad$ Cough & 0.2 & 0.3 & $0.1(n=2)$ \\
Gastrointestinal disorders & $0.1(n=0)$ & $0.2(n=1)$ & $0.2(n=1)$ & $0.1(n=4)$ \\
Vascular disorders & $0.2(n=1)$ & $0.1(n=2)$ & $0.1(n=1)$ & $0.1(n=8)$ \\
Cardiac disorders & $0.1(n=2)$ & $0.1(n=5)$ & $0.1(n=4)$ & $0.1(n=4)$ \\
Investigations & $0.1(n=1)$ & $0.1(n=3)$ & $0.1(n=2)$ & $0.0(n=3)$ \\
Surgical and medical procedures & $0.0(n=1)$ & $0.1(n=3)$ & $0.0(n=2)$ & \\
\hline
\end{tabular}


uric acid showed overall stability over the 3-month treatment period in all subgroups (Table 5). The treatment was also metabolically neutral with minor changes (or a slight trend to improvement) in the circulating plasma levels of glucose, low-density lipoprotein (LDL) cholesterol and triglycerides.

\section{DISCUSSION}

The results of this pooled analysis confirm the BP-lowering benefits of the Per/Ind SPC in patients with hypertension and T2DM and/or obesity or MetS, who were uncontrolled with previous antihypertensive treatment, and who are recognized as difficult-to-treat and at-risk populations. In particular, in the absence of clear recommendations for management of patients with hypertension and obesity and/or MetS, this 3-month study showed that the Per/ Ind SPC provided efficient BP reduction and represents a valuable therapeutic option for the physician treating such patients.

The pooled data provided sufficient numbers of patients with hypertension and each of the metabolic abnormalities for analysis: 3450 patients with T2DM, 8113 patients with obesity and 4448 patients with MetS. For each analysed subgroup, the switch to Per/Ind SPC (10/2.5 mg) provided significant BP decreases from baseline that were already observed after 1 month. After 3 months of treatment, further BP decreases were observed in all subgroups, which were quite similar to those observed in the whole cohort of 16,763 patients, and approached mean BP targets recommended by 2018 ESC/ ESH guidelines [2]. While the proportion of patients with T2DM with BP control was slightly lower than that observed in the other subgroups $(59 \%$ versus $67 \%$ of the obese subgroup, and $66 \%$ of the MetS subgroup), it should be remembered that this subgroup had a lower DBP target and so the control rate may be considered as a successful result. In addition to the BP efficacy results in the three patient subgroups, the Per/Ind SPC showed a good safety profile, including ionic $\left(\mathrm{Na}^{+}, \mathrm{K}^{+}\right)$and metabolic parameters.
For patients with hypertension and T2DM, most current treatment guidelines recommend an initial antihypertensive therapy that combines two drugs: a RAS inhibitor with a CCB or thiazide/thiazide-like diuretic $[2,5,20]$, which may then be escalated according to a treatment algorithm [2]. Some experts, however, favour more precise recommendations and suggest that the combination of a RAS inhibitor with a thiazide-like diuretic might be the best initial antihypertensive regimen for most patients with hypertension and T2DM [25, 37-39], considering that the positive effects of antihypertensive drugs on cardiovascular outcomes outweigh the potential negative effects of some agents (e.g. beta blockers, thiazide diuretics) on glucose metabolism. It should be noted that long-term trials performed with indapamide alone or combined with perindopril in T2DM populations have demonstrated the efficacy of the drugs on target organ protection with no unwanted effects on glucose metabolism [24, 40-42].

While this analysis does not present longterm results, these have been demonstrated in other trials of the Per/Ind combination, suggesting that the BP reduction would be maintained and that cardiovascular benefits would be sustained. A sub-analysis of PROGRESS (Perindopril Protection Against Recurrent Stroke Study) demonstrated a long-term (mean 3.9 years of treatment) cardiovascular benefit of Per \pm Ind versus placebo according to diabetes status [43] or BMI class [44]. Active treatment produced reductions in the risk of recurrent stroke in patients with T2DM that were at least as great as those achieved in patients without T2DM, while BP was reduced by $9.5 / 4.6 \mathrm{mmHg}$ and $8.9 / 3.9 \mathrm{mmHg}$, respectively [43]. The difference in SBP/DBP $(9 / 4 \mathrm{mmHg})$ between active treatment and placebo with no difference by BMI class provided consistent treatment benefits in terms of protection against major vascular events as well as stroke. However, the greater baseline level of cardiovascular risk in those with higher BMI meant that those patients obtained the greatest benefit [44].

In patients with T2DM, the benefits of a Per/ Ind SPC on renal protection were demonstrated in the 1 year PREMIER (Preterax in Albuminuria 


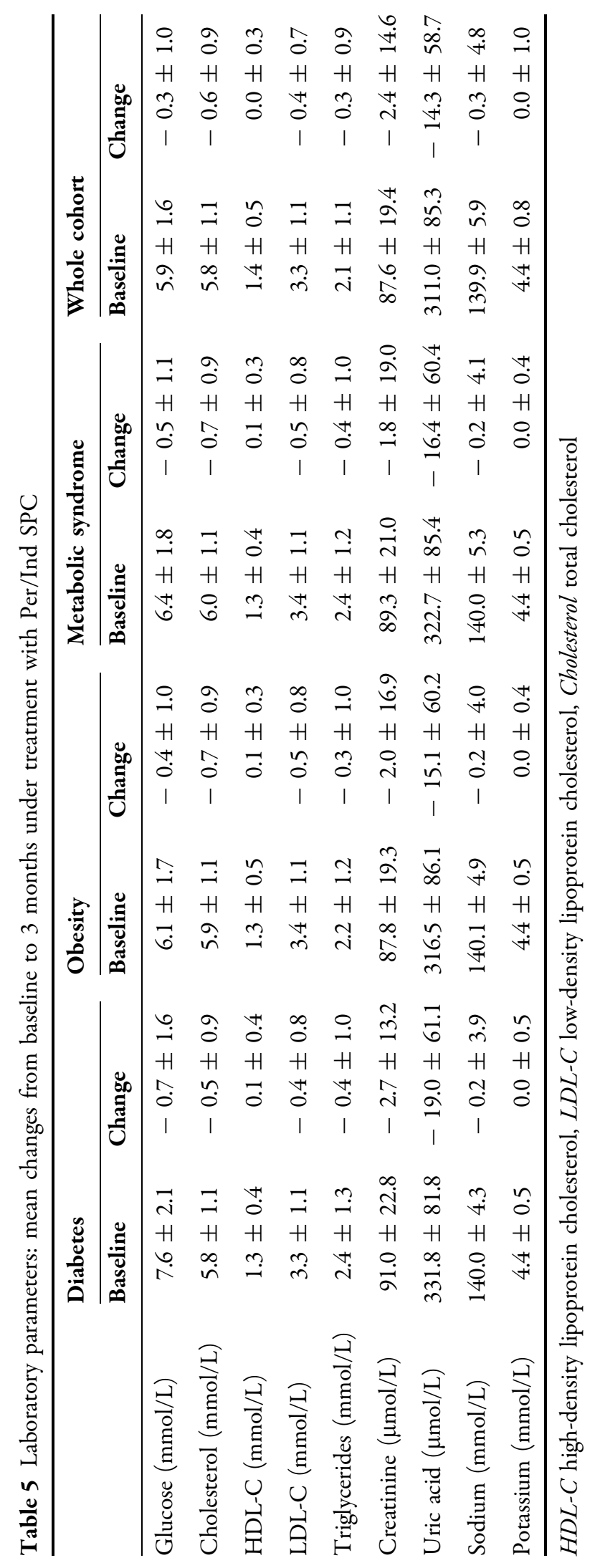


Regression) study with decreases in microalbuminuria [42] and, longer term, in the ADVANCE study [24], in which Per/Ind led to a significant $21 \%$ reduction in renal events $(p<0.001)$, including a significant reduction in the development of microalbuminuria $(p<0.0001)$. Furthermore, in a 6-year post-trial follow-up, the ADVANCE-ON study, the patients who had been treated with Per/Ind for an average of 4.5 years achieved persistent significant longterm benefits with respect to death from any cause and from cardiovascular causes $(-9 \%$, $p=0.03 ;$ and $-12 \%, p=0.04$, respectively) [45].

The benefit of ACEi for patients with T2DM has been confirmed in a meta-analysis by Iv and colleagues [46], which included 13 large trials (47,008 patients with T2DM). The results provided stronger evidence for cardiovascular benefit (including endpoints of all-cause mortality, cardiovascular death and major cardiovascular events) in the trials of ACEi compared with trials of ARBs. According to Lévy and Taddei [38], the Per/Ind combination may have important benefits that differ from other drugs in the same classes. This could be explained by a vascular legacy beyond BP control, and the known micro- and macrovascular effects of the combination, which confer clinically significant long-term benefits, some of which extend beyond the duration of treatment (as observed in the ADVANCE-ON study).

For patients with obesity, as well as those with MetS, the current guidelines for the treatment of hypertension do not provide any specific treatment recommendations. However, obesity is a key risk factor for CVD, and frequently associated with hypertension, dyslipidaemia and T2DM, all of which are major predictors of future CVD. Obesity also predisposes patients to an increased risk of atrial fibrillation, heart failure, sudden cardiac death, renal disease and ischaemic stroke, which are the main causes of cardiovascular hospitalization and mortality [47].

The benefits of a Per/Ind SPC in patients with uncontrolled hypertension and obesity and prediabetes have also been observed in a 12-week open-label study [48], which showed that the Per/Ind SPC achieved further decreases in BP over a previous losartan + hydrochlorothiazide diuretic combination. This was accompanied by improvements in arterial elasticity, alleviation of insulin resistance and inflammation. This supports previous data from randomized clinical trials where the bioequivalent Per/Ind $(8 / 2.5 \mathrm{mg})$ dose provided a significant, incremental reduction in $\mathrm{BP}$ as well as cardiac and renal end-organ protection, while remaining safe and well tolerated [49]. Beyond its BP-lowering efficacy, the Per/Ind SPC provides more effective cardiovascular protection than a monotherapy strategy. This is consistent with data from the Lombardy registry, which showed more effective cardiovascular protection with a two-drug SPC compared to monotherapy in a real-life setting [28].

The advantages of such SPCs are fully addressed in the current ESC/ESH and ISH guidelines $[2,5]$. SPCs simplify dosing for patients and improve adherence. They also facilitate treatment decisions for physicians as the drug development process ensures the correct combination of drugs at the appropriate doses.

\section{Analysis Limitations}

These studies were conducted under real-life conditions and so relatively little information was available concerning concomitant treatments received prior to or during the study that could have influenced the results. However, the large number of patients included limits the risk of uncertainty. While these observational studies had no control group, the observed BP decreases confirm previous results from randomized controlled trials [49].

Observational studies also tend to have suboptimal adverse event reporting and therefore adverse event rates should be interpreted with caution. It should be noted that different methods were used to define obesity in the included trials, with BMI (greater than $30 \mathrm{~kg}$ / $\mathrm{m}^{2}$ ) used in the Russian studies and waist circumference (greater than $102 \mathrm{~cm}$ for men, greater than $88 \mathrm{~cm}$ for women) in the Hungarian studies, which might have led to a slightly greater uncertainty in the result. However, it is 
recognized that BMI is an imperfect marker of adiposity, especially in the elderly, and that abdominal fat is probably a better way to assess cardiovascular risk [50]. An additional measure that looks promising for this objective is the concept of early vascular aging $[51,52]$, but this is still premature in its application [50].

\section{CONCLUSIONS}

The results of our subgroup analyses of patients enrolled in four large, 3-month, observational trials (FORTISSIMO, FORSAGE, PICASSO, and ACES) indicate that the Per/Ind SPC $(10 \mathrm{mg} /$ $2.5 \mathrm{mg}$ ) provides effective and well-tolerated BPlowering in patients with previously treated but uncontrolled hypertension and T2DM and/or obesity or MetS, populations in whom it is recognized that BP is difficult to control.

\section{ACKNOWLEDGEMENTS}

We thank the participants of the studies involved.

Funding. Open Access funding provided by Semmelweis University. This work and the journal's Rapid Service fee was funded by Servier, France. No funding was received for the Open Access publication of this work.

Editorial Assistance. Editorial assistance, was provided by a freelance editor, Jenny Grice, Le Prioldy, France. This assistance was funded by Servier, France.

Authorship. All named authors meet the International Committee of Medical Journal Editors (ICMJE) criteria for authorship for this article, take responsibility for the integrity of the work as a whole, and have given their approval for this version to be published.

All authors had full access to all of the data for this analysis and take complete responsibility for the integrity of the data and accuracy of the data analysis.
Disclosure. Romualda Brzozowska-Villatte is a Servier Global Medical and Patient Affairs employee and Martine De Champvallins is a Servier Institut de Recherches Internationales (IRIS) employee. Csaba Farsang, Csaba Andras Dézsi, Maria Glezer, Yuri Karpov have nothing to disclose.

Compliance with Ethics Guidelines. The designs of the individual studies in this pooled analysis were approved by local ethics committees. Information on the individual local ethics committees for each of the studies can be found in the primary study publications. All studies were carried out in accordance with the ethical principles derived from the revised Declaration of Helsinki. All patients provided written informed consent.

Data Availability. The datasets generated and/or analysed for this study are not publicly available as they include medical records of patients from a secondary source.

Open Access. This article is licensed under a Creative Commons Attribution-NonCommercial 4.0 International License, which permits any non-commercial use, sharing, adaptation, distribution and reproduction in any medium or format, as long as you give appropriate credit to the original author(s) and the source, provide a link to the Creative Commons licence, and indicate if changes were made. The images or other third party material in this article are included in the article's Creative Commons licence, unless indicated otherwise in a credit line to the material. If material is not included in the article's Creative Commons licence and your intended use is not permitted by statutory regulation or exceeds the permitted use, you will need to obtain permission directly from the copyright holder. To view a copy of this licence, visit http://creativecommons.org/licenses/by$\mathrm{nc} / 4.0 /$. 


\section{REFERENCES}

1. World Health Organization. Global health risks: mortality and burden of disease attributable to selected major risks. Geneva: World Health Organization; 2009. https://apps.who.int/iris/handle/ 10665/44203. Accessed 2 Mar 2020.

2. Williams B, Mancia G, Spiering W, et al. Authors/ Task Force Members. 2018 ESC/ESH Guidelines for the management of arterial hypertension: the Task Force for the management of arterial hypertension of the European Society of Cardiology and the European Society of Hypertension: the Task Force for the management of arterial hypertension of the European Society of Cardiology and the European Society of Hypertension. J Hypertens. 2018;36(10): 1953-2041.

3. Beaney T, Burrell LM, Castillo RR, et al. May Measurement Month 2018: a pragmatic global screening campaign to raise awareness of blood pressure by the International Society of Hypertension. Eur Heart J. 2019;40:2006-17.

4. Chow CK, Teo KK, Rangarajan S, et al. Prevalence, awareness, treatment, and control of hypertension in rural and urban communities in high-, middle-, and low-income countries. JAMA. 2013;310(9): 959-68.

5. Unger T, Borghi C, Charchar F, et al. 2020 International Society of Hypertension global hypertension practice guidelines. Hypertension. 2020;75: 1334-57.

6. World Health Organization. Global report on diabetes, 2016. https://apps.who.int/iris/bitstream/ handle/10665/204871/9789241565257_eng.pdf. Last Accessed 25 Sept 20.

7. GBD 2015 Obesity Collaborators. Health effects of overweight and obesity in 195 countries over 25 years. N Engl J Med. 2017;377(1):13-27.

8. Huang PL. A comprehensive definition for metabolic syndrome. Dis Model Mech. 2009;2(5-6): 231-7.

9. Moore JX, Chaudhary N, Akinyemiju T. Metabolic syndrome prevalence by race/ethnicity and sex in the United States, National Health and Nutrition Examination Survey, 1988-2012. Prev Chronic Dis. 2017;14:e24.

10. Scuteri A, Laurent S, Cucca F, et al. Metabolic Syndrome and Arteries Research (MARE) Consortium. Metabolic syndrome across Europe: different clusters of risk factors. Eur J Prev Cardiol. 2015;22(4): 486-91.
11. Bramlage P, Pittrow D, Wittchen HU, et al. Hypertension in overweight and obese primary care patients is highly prevalent and poorly controlled. Am J Hypertens. 2004;17:904-10.

12. Falaschetti E, Mindell J, Knott C, Poulter N. Hypertension management in England: a serial cross-sectional study from 1994 to 2011. Lancet. 2014;383(9932):1912-9.

13. Petri JR, Marso SP, Bain SC, et al. LEADER-4: blood pressure control in patients with type 2 diabetes and high cardiovascular risk: baseline data from the LEADER randomized trial. J Hypertens. 2016;34: 1140-50.

14. Jordan J, Yumuk V, Schlaich M, et al. Joint scientific statement of the European Association for the Study of Obesity and the European Society of Hypertension: obesity and difficult to treat arterial hypertension. J Hypertens. 2012;30:1047-55.

15. Rao A, Pandya V, Whaley-Connell A. Obesity and insulin resistance in resistant hypertension: implications for the kidney. Adv Chronic Kidney Dis. 2015;22(3):211-7.

16. Vishram JKK, Borglykke A, Andreasen AH, et al. Impact of age and gender on the prevalence and prognostic importance of the metabolic syndrome and its components in Europeans. The MORGAM Prospective Cohort Project. PLoS One. 2014;9(9): e107294.

17. Thoenes $M$, Neuberger H-R, Volpe $M$, Khan BV, Kirch W, Bohm M. Antihypertensive drug therapy and blood pressure control in men and women: an international perspective. J Hum Hypertens. 2010;24:336-44.

18. Kotchen TA. Obesity-related hypertension: epidemiology, pathophysiology, and clinical management. Am J Hypertens. 2010;23:1170-8.

19. Thomopoulos C, Parati G, Zanchetti A. Effects of blood-pressure-lowering treatment on outcome incidence in hypertension: 10-should blood pressure management differ in hypertensive patients with and without diabetes mellitus? Overview and meta-analyses of randomized trials. J Hypertens. 2017;35(5):922-44.

20. Whelton PK, Carey RM, Aronow WS, et al. ACC/ AHA/AAPA/ABC/ACPM/AGS/APhA/ASH/ASPC/

NMA/PCNA guideline for the prevention, detection, evaluation, and management of high blood pressure in adults: a report of the American College of Cardiology/American Heart Association Task Force on Clinical Practice guidelines. J Am Coll Cardiol. 2018;71:e127-248. 
21. Owen JG, Reisin E. Anti-hypertensive drug treatment of patients with and the metabolic syndrome and obesity: a review of evidence, meta-analysis, post hoc and guidelines publications. Curr Hypertens Rep. 2015;17(6):558.

22. American Diabetes Association. 9. Cardiovascular disease and risk management: standards of medical care in diabetes-2018. Diabetes Care. 2018;41(Suppl 1):S86-104.

23. Buse JB, Wexler DJ, Tsapas A, et al. 2019 Update to: management of hyperglycemia in type 2 diabetes, 2018. A consensus report by the American Diabetes Association (ADA) and the European Association for the Study of Diabetes (EASD). Diabetes Care. 2020;43(2):487-93.

24. ADVANCE Collaborative Group. Effects of a fixed combination of perindopril and indapamide on macrovascular and microvascular outcomes in patients with type 2 diabetes mellitus (the ADVANCE trial): a randomised controlled trial. Lancet. 2007;370:829-40.

25. Wenzel UO, Benndorf R, Lange S. Treatment of arterial hypertension in obese patients. Semin Nephrol. 2013;33(1):66-74.

26. Dézsi C, Glezer M, Karpov Y, Brzozowska-Villatte R, Farsang C. Effectiveness of perindopril/indapamide single-pill combination in uncontrolled patients with hypertension: a pooled analysis of the FORTISSIMO, FORSAGE, ACES and PICASSO observational studies: experience with Per/Ind 10/2.5 mg in daily clinical practice. Adv Ther. 2020. https:// doi.org/10.1007/s12325-020-01527-3.

27. Wald DS, Law M, Morris JK, et al. Combination therapy versus monotherapy in reducing blood pressure: meta-analysis on 11,000 participants from 42 trials. Am J Med. 2009;122:290-300.

28. Rea F, Corrao G, Merlino L, Mancia G. Early cardiovascular protection by initial two-drug fixeddose combination treatment vs. monotherapy in hypertension. Eur Heart J. 2018;39(40):3654-61.

29. Dézsi CA, Glezer M, Villatte R, Karpov Y, Farsang C. Effectiveness of perindopril/indapamide single-pill combination in uncontrolled hypertensive obese patients: a combined analysis of FORTISSIMO, FORSAGE, ACES and PICASSO observational studies. J Hypertens. 2018;36:S3.

30. Farsang C, Dézsi CA, Villatte R, Glezer M, Karpov Y. Effectiveness of perindopril/indapamide single-pill combination in uncontrolled hypertensive patients with diabetes: a combined analysis of FORTISSIMO, FORSAGE, ACES and PICASSO observational studies. J Hypertens. 2018;36:pe203.
31. Karpov YA. Full-dose perindopril/indapamide in the treatment of difficult-to-control hypertension. The FORTISSIMO Study. Clin Drug Investig. 2017;37:207-17.

32. Glezer MG, Deev AD. How to increase the effectiveness of antihypertensive therapy in clinical practice. Results of the Russian Observational Program FORSAZH. Kardiologiia. 2016;56(1):18-24.

33. Nadhazi Z, Dezsi CA. The results of ACES (Antihypertensive Combinations' Long Term Efficacy Comparing Study): analysis of metabolic effects of antihypertensive combination therapies. Clin Drug Investig. 2016;36:819-27.

34. Farsang C. Blood pressure and metabolic efficacy of fixed-dose combination of perindopril and indapamide in everyday practice. Blood Press. 2013;22(Suppl. 1):3-10.

35. Farsang C. Efficacy and tolerability of fixed-dose combination of perindopril/indapamide in type 2 diabetes mellitus: PICASSO. Adv Ther. 2014;31: 333-44.

36. National Cholesterol Education Program (NCEP) Expert Panel on Detection, Evaluation, and Treatment of High Blood Cholesterol in Adults (Adult Treatment Panel III). Third Report of the National Cholesterol Education Program (NCEP) Expert Panel on Detection, Evaluation, and Treatment of High Blood Cholesterol in Adults (Adult Treatment Panel III) final report. Circulation. 2002;106(25): 3143-421.

37. Ferrannini E, Cushman WC. Diabetes and hypertension: the bad companions. Lancet. 2012;380(9841):601-10.

38. Lévy BI, Taddei S. Vascular legacy beyond blood pressure control: benefits of perindopril/indapamide combination in hypertensive patients with diabetes. Curr Med Res Opin. 2018;34(9):1557-70.

39. Burnier M, Bakris G, Williams B. Redefining diuretics use in hypertension: why select a thiazidelike diuretic? J Hypertens. 2019;37(8):1574-86.

40. Marre M, Garcia Puig J, Kokot F, et al. Equivalence of indapamide SR and enalapril on microalbuminuria reduction in hypertensive patients with type 2 diabetes: the Nestor study. J Hypertens. 2004;22: 1613-22.

41. Garcia Puig J, Marre M, Kokot F, et al. Efficacy of indapamide SR compared with enalapril in elderly hypertensive patients with type 2 diabetes. Am J Hypertens. 2007;20(1):90-7.

42. Mogensen CE, Viberti G, Halimi S, et al. Effect of low-dose perindopril/indapamide on albuminuria 
in diabetes: Preterax in albuminuria regression: PREMIER. Hypertension. 2003;41:1063-71.

43. Berthet K, Neal BC, Chalmers JP, et al. Reductions in the risks of recurrent stroke in patients with and without diabetes: the PROGRESS trial. Blood Press. 2004;13(1):7-13.

44. Czernichow S, Ninomiya T, Huxley R, et al. Impact of blood pressure lowering on cardiovascular outcomes in normal weight, overweight, and obese individuals: the Perindopril Protection Against Recurrent Stroke Study trial. Hypertension. 2010;55:1193-8.

45. Zoungas S, Chalmers J, Neal B, et al. Follow-up of blood-pressure lowering and glucose control in type 2 diabetes. $N$ Engl J Med. 2014;371(15): 1392-406.

46. Iv X, Zhang Y, Niu Y, et al. Comparison of angiotensin-converting enzyme inhibitors and angiotensin II receptor blockers on cardiovascular outcomes in hypertensive patients with type 2 diabetes mellitus A PRISMA-compliant systematic review and meta-analysis. Medicine. 2018;97(15): e0256.

47. Kotsis V, Jordan J, Micic D, et al. Obesity and cardiovascular risk: a call for action from the European Society of Hypertension Working Group of Obesity, Diabetes and the High-risk Patient and European Association for the Study of Obesity: part A: mechanisms of obesity induced hypertension, diabetes and dyslipidemia and practice guidelines for treatment. J Hypertens. 2018;36(7):1427-40.

48. Nedogoda SV, Barykina I, Salasyuk A, Smirnova VO, Popova E. Optimization of blood pressure control, metabolic parameters, and target organs protection with perindopril + indapamide fixed combination in hypertensive patients with obesity and prediabetes. Diabetes. 2018;67(Supplement 1). https:// doi.org/10.2337/db18-129-LB.

49. Mourad JJ, Lejeune S. Evaluation of high dose of perindopril/indapamide fixed combination in reducing blood pressure and improving end-organ protection in hypertensive patients. Curr Med Res Opin. 2009;25(9):2271-80.

50. Jordan J, Nilsson PM, Kotsis V, et al. Joint scientific statement of the European Association for the Study of Obesity and the European Society of Hypertension: obesity and early vascular ageing. J Hypertens. 2015;33(3):425-34.

51. Nilsson PM, Boutouyrie P, Laurent S. Vascular aging: a tale of EVA and ADAM in cardiovascular risk assessment and prevention. Hypertension. 2009;54:3-10.

52. Kotsis V, Stabouli S, Karafillis I, Nilsson P. Early vascular aging and the role of central blood pressure. J Hypertens. 2011;29:1847-53. 